\title{
Identifying, Understanding and Preventing Cyber Bullying
}

\author{
Ria Hanewald \\ Deakin University, Australia
}

\begin{abstract}
This paper presents definitions on cyber bullying, its various forms and their characteristics and background information. An examination of empirical studies on cyber bullying was conducted to provide an overview of the literature, extract and list the ten key issues found in there and discuss their implications. In response to increase incidents reports of harmful activities in digital environments, governments, educational authorities, protection agencies, educators, parents and young people themselves are interested in reducing incidents and enabling safe experience online. Approaches include the installation of Internet filters and blocks, new legislation to deter potential online predators and persecute offenders, and cyber safety programs to educate young people about ways in which they protect themselves from offensive content or inappropriate contacts. However, as young people create, remix and share digital content they often inadvertently cyber bully others or produce content for which they can be held liable and suffer severe consequences. Therefore, this paper aims to endow help reader with the necessary information to identify, understand and prevent cyber bullying.
\end{abstract}

\section{Introduction}

Computers, web 2.0 applications and mobile communication have become an integral part of contemporary society around the globe. The Organisation for Economic Co-operation and Development (OECD) [1] indicated a raise in the level of Internet penetration of all households in 34 countries. The average Internet access in 2007 was $58 \%$ which had increased to $72 \%$ by 2010 .

In Australia, 98\% of Australian families own a computer, nine in ten families now have the Internet and $76 \%$ have broadband. There is at least one mobile phone in every family; most families have three mobile phones. Young people (aged eight to 17 years) spent an average of 49 minutes per day communicating online. Thirty-nine per cent had a personal profile on a social networking site (for example Bebo, Edmodo, Facebook, Hi5, MySpace,Orkhut). On average, 11 minutes per day were spent on social websites, five minutes on emails, 15 minutes online gaming and 18 minutes on messaging and chatting [2]. Aged between 5 and 8 years $60 \%$ of those children used the Internet. By the time they were between 12 and 14 years of age this had increased to $96 \%$ of children. The majority $(85 \%)$ used the Internet for educational purposes, to play online games $(69 \%)$ or to access Social Networking Sites (22\%) [3].

In the United Kingdom, the level of internet use is similar with $90 \%$ of young people aged between 5 and 16 years having a computer and mobile phones, with $99 \%$ of young people between 8 and 17 years being able to access the Internet either in their own home or at school [4]. The statistics are similar in the United States where 93\% of young people between 12 and 17 years are accessing the Internet [5].

In the European Union (EU) young people between 9 and 16 years will spend 88 minutes online each day, which rises to 11 minutes by the time they are between 15 and 16 years old. Most (87\%) access the Internet at home or at school (63\%) [6]. Young people between 13 and 16 years watched YouTube (86\%), communicated via email, Social Networking Sites or Instant messenger $(75 \%)$ or visited chatrooms or virtual worlds, shared files and blogged (23\%) [7]. While the Internet offers enormous potential to access educational content to support young people's learning, entertainment, communicating and socializing with others, it also holds the potential to access offensive (e.g. pornographic, violent, racist) materials, inappropriate contact and communication with criminals (e.g. pedophiles, political terrorists, religious fanatics).

The more time young people spent online, they more the risk increases, especially for cyber bullying [8]. For example, in Australia during 2009 alone, approximately 72,000 young people had personal safety or security problems on the internet [2]. However, young people's online safety is not only a problem for Australia, Europe, the United Kingdom or the United States. It is a global problem for governments, protection agencies and educational authorities around the world. They are concerned for young people's safety online and therefore have commit substantial funding for the development of educational resources and the provision of Internet filters and blocks to improve online safety. Efforts have also been made to introduce new legislation and increase law enforcement with the aim to dissuade potential online perpetrators as well as to capture, punish and frighten offenders.

Despite these multi-pronged efforts to ensure safe and beneficial experiences for young people through networked and mobile communications, cyber bulling has exploded world-wide between 2000 and 2010 [9]; [10]; [11]; [12]; [13]. 
This paper endeavors to increase awareness and understanding of cyber bullying; illuminating the concerns to stimulate professional and public debate, with the view to addressing the issues and ultimately eradicating or at least decreasing cyber bullying incidents.

\section{Literature review}

This section summarizes the empirical research and identifies ten key themes that are emerging from the body of work. Following the identification of cyber bullying, it unpacks the complexity of these issues and paves the way for a discussion on the implications in terms of prevention and intervention approaches.

\subsection{Definition of cyber bullying}

Cyber bullying (also spelled cyber-bulling) is the most commonly used term by scholars ([9]; [10]; [11]) to describe a range of intentionally harmful activities conducted through mobile and networked technologies. Other terms include online harassment, online bullying or electronic bullying, which also comprise the abusing, threatening or harassing of others either through electronic devices such as mobile or smart phones, Personal Digital Assistants (PDAs), tablet s(e.g. iPad, Android), laptops, netbooks, and desktops.

The term derives from traditional also called face-to-face or real life (versus cyber space) bullying in schools or playground, which often involves physical (for example hitting, pushing, kicking, spitting) and verbal abuse (for example name calling, swearing, cursing, threats) [14].

There are those who argue that cyber bullying is merely a shift from physical environments to online environments [15], while others [16] see it as an extension of bullying in school (for example to retaliate or seek revenge while hiding behind a computer screen). Both traditional and cyber bullying have in common that it they are equally unwanted, deliberate and persists [16]. The difference is the mode (face-to face versus online), the frequency (traditional bullying is decreasing, cyber bullying is increasing); time frame (cyber bullying happens any time, traditional bullying only before, during or after school); audience (traditional bullying as only immediate bystanders, cyber bullying has an infinite, global audience of on-lookers); the impact (cyber bullying is more damaging than traditional bullying); the identity of the perpetrator (traditional bullies are easily identified, cyber bullies are anonymous); the primary targets (for traditional bullying it is boys, for cyber bullying it is girls); the duration (cyber bullying occurs more frequently and is harder to stop than traditional bullying); reports to adults (the majority of cyber bullying goes unreported); the low rate of intervention by teachers or school administrator (they are unaware of cyber bullying as it is "invisible" compared to school yard bullying); the low rate of punitive action (traditional bullying is followed up with some form or disciplinary action such as detention or suspension, cyber bullying allows the perpetrator to remain anonymous, which prevents any follow up); and the rate of conversion from by- stander to bully (miniscule in traditional bullying but high in cyber bullying due to the anonymity of the bully and the lack of discovery and percussions which aids the temptation for a passive onlooker to turn into an active cyber bully) [14].

Apart from commonalities and differences, the research field of cyber bullying and thus the existing body of literature suffers from an inconsistency in classifying the gamut of inappropriate online behavior. It creates a problem of definitional clarity and an inability to compare data from various researchers or countries. Meaningful cross-study comparison is problematic if cyber bullying behaviors are labeled with divergent terms and different definitions, depending on the author's own interpretation [8]; [9]; [10]; [11]; [12].

This confusion or lack of agreement in the field also hampers the evaluation of prevention and intervention programs as the measurement of their effectiveness is attempted against similar but not identical terminology and definitions [14]. For example, the term of cyber violence was used by one researcher to indicate harassment, degradation, denigration and online contact with subsequent offline harm. Another researcher used the term of cyber bullying which included cyber stalking, denigration and flaming while yet another used the same umbrella term of cyber bullying but included denigration, flaming, masquerading, exclusion / ostracism as well as outing and trickery. Yet another researcher investigated internet harassment rather than bullying [17].

The inconsistencies are becoming even greater when researchers from non-English speaking countries publish their results as they either translate with approximation or use terminology from their own language, which hinders online searches of their work. For example, in continental Europe and its appearing literature the term of "(cyber) mobbing" and to a lesser extent "(cyber) harassment" is used for (cyber) bullying.

In addition to this bewilderment, there are also divergent views on the severity of certain behaviors compared to others, their impact on the perpetrator, victims and bystander and how they are linked together. It makes accurate labels and definitions important not only to establish a common terminology and universal language but also to create a shared understanding [14]. 
Unless identical criteria for classifications are used it will be difficult to measure the nature of something if its nature is not defined. It is also difficult to measure the extent of a phenomenon, if the measurement time periods vary significantly. For example, some researchers ask participants to recall incidents of cyber bullying either within the last week, last months, last six months or even last year. These are salient points and need to be kept in mind when reading the existing literature and as long as there is no agreement or universal definition.

\subsection{The emergence of cyber bullying}

The risk in electronic environments was recognized as early as 1999 with the US based research team of Finkelhor, Mitchell \& Wolak [13]. They released their study in 2000 titled Online victimization: A Report on the Nations' Youth. A follow up five years later with an identically composed group of 1,500 Internet teenage users aged 10-17 years and found that cyber bullying had increased from $28 \%$ to $48 \%$. This happened despite considerable funding for Internet safety programs and growing use of computer filtering and blocking software.

Meanwhile, a similar sized group $(1,566)$ of younger children (aged 8-12 years) National i-Safe Survey was conducted in 2004 by the American based Foundation for Internet Safety Education. More than half $(57 \%)$ of those students in primary school had received hurtful comments, $35 \%$ of students had been threatened and $42 \%$ had been bullied online [18].

In Britain, the National Children's Home [19] conducted the first-ever survey of 770 young people aged 11 to 19 years and found that amongst the $16 \%$ of cyber bullied teenagers "...bullying or threat via email, internet chat room or text" was no longer a once-off experience but a repeated occurrence. The trend increased markedly within four years with $22 \%$ of young people cyber bullied at least once and almost $7 \%$ affected several times in a study of 952 teenagers (aged 11-16 years) [19].

\subsection{The rise of cyber bullying}

The fact that cyber bullying is a significant phenomenon and the rapid rise in cyber bullying over the last years are the two greatest concerns. This is particularly evident in the work of the research team consisting of David Finkelhor, Kimberley Mitchell and Janis Wolak who repeated a study within a five year interval that is in 2000 and again in 2005. The first study of 1500 young people (aged 10 to 17 years) indicated cyber bullying at $28 \%$ which rose to $48 \%$ within a five year period [13]; [20]. This increase occurred despite blocking software, internet filters, as well as programs to educate children and thus prevent cyber bullying.

The notion that cyber bullying was increasing was shared by Year 8 students in Queensland, which revealed that out $14 \%$ were cyber victims and $11 \%$ identified themselves as cyber bullies out of a group of 120 children [21]. Almost 25\% of 177 students in Year 7 were cyber bullied in Canada [22]. In Serbia, $10 \%$ of 11 to15 year old middle school students admitted to being cyber bullies while $20 \%$ were victims of cyber bullying [23].

The data indicates the rise of cyber bullying with a trend towards further increase as young people develop more proficiency in the use of digital media and because electronic tools have become cheaper and more readily accessible.

\subsection{Use of technologies for cyber bullying}

Phone calls, text messages and email were the most widespread form of cyber bullying, with chat room bullying the least common [24] It was found when analyzing questionnaires filled out by 92 school students (between 11 and 16 years) across 14 different schools in London [24]. Another British study by the National Children's Home [19] ranked text messages $(14 \%)$, chat rooms $(5 \%)$ and email (4\%) as the most commonly used tools for cyber bullying. In Sweden, cyber bullying through text messages rated barely $5 \%(4.8 \%)$, emails $(9 \%)$, pictures and/or video clips $(8.6 \%)$ with phone calls reached almost $7 \%(6.7 \%)$ in the past two to three months [25].

Mark and Ratliffe [26] found that the 6th, 7th and 8th graders in their study of two Hawaiian schools used MySpace and mobile phones equally (both $29 \%$ ) as prevalent type of technology for cyber bullying. Instant messenger (13\%), online games $(11 \%)$, email (8\%), chat rooms $(6 \%)$, YouTube $(3 \%)$ and Internet websites $(1 \%)$ were also used.

Australian cyber bullies used mostly text messages, followed closely by chat rooms and then by electronic mailing [27]. Price and Dalgleish [28] also surveyed Australian students, with email (21\%), online chatrooms (20\%), social networking sites $(20 \%)$, mobile phones $(19 \%)$ and internet website $(8 \%)$ used for cyber bullying in the sample of 548 participants. Almost $41 \%$ of cyber bullying in Canada took place through multiple sources (i.e. email, chat room, mobile phone) [15].

\subsection{Identifyingand reporting of cyber bullying}

There was a marked lack of public awareness on cyber bullying in the early years of the decade, which may have been due to the lack of reporting. For example, although 892 out of 1,566 
children across Grade 4 to 8 had received hurtful comments, 548 were threatened and 657 were bullied online or with mobile communication tools, most (58 $\%$ ) did not tell their parents or another adult [18].

Dooley, Gradinger, Strohmeier, Cross and Spiel [27] found in a study of 7489 young people with a median age of 12.52 years that girls were significantly more likely to report incidents and seek help than boys. They hypothesis that the majority of cyber bullying is relatively mild (compared to other bullying behavior) and that victims may have had the skills to deal with these incidents by themselves and therefore sought no help.

The reasons for not reporting was in $31 \%$ of young people their opinion that it was not a problem, $12 \%$ had no one they wanted to tell, $11 \%$ thought it would not stop the bullying or threats and $10 \%$ did not know how to get help. The under reporting might be due to a lack of adult presence and supervision, particularly of teachers as $50 \%$ of cyber bullying happened at school or college. About $21 \%$ of cyber bullying took place after school, $17 \%$ during the weekend; and 6\% during the school holidays [19]. The low reporting rate of cyber bullying by young people might be due to a fear that internet use will be restricted or eliminated. This seems to be supported by the findings of the American i-Safe survey, which questioned 4,500 parents and students from Grade 5 to Grade 12 . Almost a third of young people (29\%) knew that their parents would object to their online activities if they knew what they were doing. While $87 \%$ of parents had established rules for their children's Internet use, more than a third $(36 \%)$ of parents had not discussed how to stay safe online with their children, according to them. The $31 \%$ of young people not viewing cyber bullying as a problem concurs with a third of young people's (29\%) awareness that their parents would object to their online activities if they knew what they were [29].

Another reason might be that adult assistance may not be useful. Cross, Shaw, Hearn, Epstein, Monks and Lester [29] discovered that $46 \%$ of bully victims revealed that their situation either got worse or did not improve after they reported to an adult that they were being bullied. Cross et al. [29] suggested that this was due to adults lacking skills in dealing with cyber bullying incidents. Mark and Ratliffe [26] established that the 247 middle school students in their study believed that the adults in their lives (teacher and parents) were not prepared to help them with cyber bullying problems.

\subsection{Age and gender factors in cyber bullying}

Cyber bullying peaks around 13 years of age as a Canadian survey of 3,700 middle school students revealed [30]. Ybarra und Mitchell [31] discovered that American High School students are more likely to engage in cyber bullying than middle school students $(n=1500)$. Older students engaged more in cyber bullying according to Smith, Mahdavi, Carvalho, Fisher, Russell and Tippet [24]. They identified that $8 \%$ of students in Year 7 were cyber bullies, which had risen to $12 \%$ by middle school (Year 8 and 9) and almost a quarter of students $(23 \%)$ in Year 10 and 11.

Respectively, on the receiving end of cyber bullying were $14 \%$ of Year 7 students. This figure for cyber victims had risen to $19 \%$ by middle school and $26 \%$ in the final years. Price and Dalgleish's study [27] of 548 Australians found that cyber bullying occurred mostly in the period of transition from primary to secondary school. Their participants experienced cyber bullying at multiple ages when growing up, with the range being from 10 to 16 years.

Chu [30] also found distinctive gender variations in the previously mentioned study of 3,700 Canadian middle school students, with only $10 \%$ of boys but $30 \%$ of girls being cyber bullies. Several other studies also discovered a gender difference such as Finkelhor, Mitchell \& Wolack [12] who found that the number of girls targeted for cyber bullying is twice as much as those for boys in a sample of 1500 teenagers.

Li [38] and Smith, Mahdavi, Carvalho \& Tippet [39] believe that females are much more often involved in cyber bullying than males, both as bullies and as victims. The latter researcher also found gender differences in the modes used for cyber bullying, with girls using mobile phones and chatting while boys used text messages and to a less extent pictures or video clips for bullying on websites [24]. A study of 264 Canadian junior high school students discovered that cyber bullying incidents involved more boys than girls [27]. Conversely, Kowalski and Limber [11] and the Swedish researcher team of Slonje and Smith [25] established that more girls than boys are cyber bullying victims. A study of 1500 American students in Grade 4 to 8 indicated that cyber bullying was more likely to be initiated by boys than by girls. Boys were also more often cyber bullied but less likely to report it to adults than girls [18]. In Popovic-Citic, Djuric and Cvetkovic' study [23] of 387 middle school students in Belgrade, the male 11 to 15 year old reported higher levels of bullying others and being victimized by cyber bullies than their female counterparts. Mark and Ratliffe [26] found that of the 247 middle school children in their study, $33 \%$ of girls and 20 $\%$ of boys reported being involved in a cyber bullying incident either as bully or victim. The reasons for these variations in findings on gender differences are unclear, it could be speculated that they are due to cultural differences in the various countries, educational institutions and families of the young people. 


\subsection{Identity of the cyber bully}

There is some disagreement in the literature on the identity of the cyber bully. While $\mathrm{Li}$ [15] found that $41 \%$ of cyber victims (in a study of 177 Canadian middle school students) did not know the identity of the cyber bully, a survey by the National Children's Home [19] found that $73 \%$ of cyber victims knew their cyber bully's identity, within a sample of 700 children aged 10 to 11 years. It seems to indicate an established relationship between the cyber bullies and their victims, which might explain the motive for the online abuse.

\subsection{Location and time of cyber bully}

Findings on the physical location and time of cyber bullying are conflicting. The British National Children's Home [19] for example found that nearly half of all cyber bullying (48\%) occurred at school or college. Unsupervised time combined with easy access to computers might facilitate inappropriate use. The study also found that $21 \%$ of cyber bullying occurred after school or college, $17 \%$ was done during the weekend and $6 \%$ happened during school holidays. The low rate of incidents during school holidays and on weekends might be attributed to travel and leisure activities; with schedules reducing opportunities to use the internet.

Contrary, the British scholars Smith, Mahdavi, Carvalho and Tippet [24] found that cyber bullying is mostly done outside school. Lower rates of cyber bullying in schools might be attributed to close supervision by teachers. Another factor might be electronic filters, Internet blocks or a secure internal network (Intranet) that prohibits students' access to certain sites (for example Bebo, Facebook, MySpace, Edmodo for social networking or chat forums) and prevent engagement.

Also, most schools nowadays have an "Acceptable Use Policy" (AUP), which specifies the guidelines for Internet use at school. This code of conduct often includes a section on "netiquette" and outlines the possible repercussion for any violations. These can include mild punitive measurements such as loss of Internet access privileges for a limited time or more severe punishments such as detention or even expulsion from school. At home, computers are often in children's bedrooms, making parental supervision difficult. For example, almost half (49\%) of the young people in Europe accessed the Internet from their bedroom [7]. Furthermore, the advent of affordable handheld devices such as smart phones, tablet, laptops and netbooks combined with wireless access to the Internet anywhere in the house further hinders parents from monitoring their children's online activities. Parents' lack of technical skills might be the reason why protective software is not installed or perhaps outdated on the home computer.

\subsection{The impact of cyber bullying}

The actual impact of cyber bullying had been investigated by Beran \& Li [32] who uncovered that $57 \%$ of cyber bullied students in Year 7 felt angry and 37\% felt sad and hurt amongst a group of 264 Canadian adolescents. Mitchell, Ybarra and Finkelhor [33] established that cyber bullied students display a range of problematic behaviors such as drinking of alcohol, smoking, poor academic performance at school and depressive symptoms. Mark and Ratliffe [26] identified the consequences of cyber bullying as "...poor academic performance, school dropout, physical violence, and suicide..." Perren, Dooley, Shaw and Cross [34] ascertained with their study of1694 students (median age of 13.8) that victims of cyber bullying reported significantly higher levels of depressive symptoms than victims of traditional bullying and on-involved young people. Price and Dalgleish [27] identified the most common areas of negative impact as selfconfidence $(78 \%)$, self-esteem $(70 \%)$ and friendship $(42 \%)$ in their survey of 548 Australians aged between 10 and 16 years.

\section{Methodology}

In September 2011, a Boolean search with combination of key terms (i.e. bullying, cyber, computer, electronic, internet) was run across ten data bases (A+ Education, ERIC, JSTOR, World Cat, Web of Science, etc.) to identify English language, peer-reviewed academic journals or research reports focusing on peer to peer bullying in students of either primary or secondary school age. Excluded were all articles that: 1) dealt with bullying but not cyber bullying, 2) investigated cyber bullying of teachers from students but not student to student cyber bullying, 3) were not based on primary or secondary school aged students, 4) were not written in or translated to English, 5) were not peer-reviewed empirical publications.

\section{Discussion}

The search criteria identified mostly empirical studies in Australia, Canada, the UK or the USA with the typical research participants being teenagers (between 11 and 19 years old). The majority of early work focused on the extent and mode of cyber bullying incidents, followed by the places and times when cyber bullying occurred. There was some data available on the age and gender differences in cyber bullying incidents but less data on reporting of incidents from cyber victim to adults 
or authorities and their reactions. There was also lesser exploration on the parallels and interrelationship between face-to-face bullying and cyber bullying, the motive for cyber bullying, the impact on the victim and the behavior and attitude of the bystanders.

\subsection{Major themes from the literature}

In summary, ten themes can be identified across the body of literature:

- $\quad$ cyber bullying as a significant phenomena

- the rapid increase of cyber bullying

- preferred electronic tools and activities for cyber bullying

- a general lack of reporting by young people to adults and /or authorities

- age differences, with increases from the middle years to the final school years

- gender differences, with contradictory findings by researchers

- identity/ anonymity of the offender

- occurrence of cyber bullying (location, time, frequency)

- impact of cyber bullying on the victim, the bully and any bystanders

- comparison and relationship between traditional bullying and cyber bullying

\subsection{Other emerging issues}

One issue worth noting is the substantial funding has been committed for prevention and intervention to reduce cyber abuse [35]; [36] and the lack of evaluation on the absolute and comparative usefulness of suggested approaches.

\subsubsection{Effectiveness of prevention and intervention approaches. The financial provisions by government, educational authorities and child protection agencies to enable large scale cyber safety and anti-bullying initiatives is aided by committed individuals, non- profit or community organization and researchers who might be piloting prevention or intervention approaches. The range of activities include cyber safety stickers, posters or badges to raise awareness; pamphlets, brochures or information kits to educate on cyber safety; training sessions that are delivered either face-to-face or online for parents, teachers and children to coach participants about strategies; interactive self-paced online tutorials to train individuals in cyber safety; telephone help-lines or email options to report inappropriate content or contact; tuition to instruct parents or administrators how to install internet blocking or filtering software and so on.}

The rising prevalence rates of cyber bullying incidents (as discussed earlier) combined with the negative impact on the social, emotional and physical well-being of young people and the deterioration of their academic achievement has caused the range of cyber safety initiatives and the finances to fund these. Although the immediate response and intention are commendable, there is no empirical evidence in the scientific literature that these initiatives are effective at all. One of the reasons (as discussed earlier) is current confusion on terminology and the nature of cyber bullying, which makes measuring its rate of prevalence and the impact of any intervention programs problematic. The challenge will be to identify the specific cyber bullying behaviors that are to be prevented and subsequently measured and in which online or mobile environment prevention initiatives should take priority and how these measurement of effective programs should be conducted. Currently, the research field on cyber bullying is still in its infancy and is only now maturing to a stage where measurement instruments are being developed and trialed. The pertinent question in that particular context would be in relation to the overall purpose of a measurement tool.

4.1.2. Cyber suicide and legislation. The fear of cyber suicide (suicide related to cyber bullying) has further contributed to cyber bullying prevention efforts. Cyber suicides were reported in the mass media early as7 October 2003 in the case of Ryan Patrick Halligan who hanged himself at 13 years of age after online rumors that he was gay. Aged 13 Megan Meier ended her life on 16 October 2006 because she was cyber bullied through the social networking site MySpace. It caused the first cyberbullying and cyberstalking state laws to protect children and the introduction of the "Megan Meier Cyberbullying Prevention Act" in the US on 22 May 2008.

4.1.3. Mandatory training and protection. Unsurprisingly, $73 \%$ of young people acknowledge that there is a need to learn about Internet safety [18]. In schools, cyber safety training is not a mandatory part of the curriculum, nor is it part of teacher education courses which may find many teachers unprepared for handling cyber bullying in their classrooms. The attempt to protect young people by installing firewalls and internet filters is of little avail as the example of Tom Wood, a sixteen-year old school boy from Melbourne showed. He hacked through the Australian governments' new \$ 84 million Internet porn filter within 30 minutes [37].

4.1.4. Mobile devices and sexting. The invention and affordability of smart phones combined with 
wireless connections to the web in the last three years has seen the rise of cyber bullying due to cheap, easy and convenient Internet access. Young people are able to take photos or videos about anyone and post them online. This caused the emergence of sexting, which is the sending or receiving of sexually explicit messages via mobile phones. It usually involves teenagers who are taking semi or fully nude pictures either of themselves or of others and distribute these digitally. The teenager who takes (semi) nude photos of themselves and forwards these images to their romantic interest with the intention most often intents that these pictures are only to be viewed by this (potential) lover. However, these pictures can easily be circulated and thus seen by a wide circles of peers, perhaps even posted online for the whole world to see, which is potentially highly embarrassing and difficult to retract especially if the images have gone viral. Other teenagers might be unaware of the existence of these images if they were intoxicated at the time or if the pictures were secretly taken for example in the school's change room after physical education classes or such like.

American Research on 10 to 18-year-olds $(\mathrm{N}=4441)$ indicated that $15.9 \%$ of males (compared to $9.9 \%$ of females) received naked or semi-naked images of someone from their school via a mobile phone (statistically significant $\mathrm{p}=.001$ ), whereas $8.2 \%$ of males (compared to $7.2 \%$ of females) sent them $(\mathrm{p}=.021)$ to others [40]. There are currently no reliable statistics on sexting in Australia due to the short availability of the technology. However, the potential harm is illustrated by the case of a Queensland teenager with a topless photo of a 15year-old girl on his phone who was charged with possessing child exploitation materials [41]. In response to such behavior, the Australian Government is educating about the dangers of sexting as part of its $\$ 120$ million cyber safety program [42]. Although teenagers involved in romantic and sexual relationships may consent to sharing semi (nude) pictures of themselves, when these images are found by disapproving parents for example, legal action can follow which might result in a conviction. A guilty verdict in relation to child pornography will prevent the sentenced teenagers from any future career in law or law enforcement (for example police officer, lawyer), education (for example child care worker, teacher, lecturer) or similar.

Sexting can be a form of cyber bullying if the person on display has not consented to the pictures or their distribution. Even if sexting is consensual due to the teenager's ignorance about possible implications, its consequences and their severity will still apply.

\section{Findings}

Cyber bullying among school aged students is a growing problem. Young people, parents, and teachers need to be educated on the damage that cyber bullying causes. These include delinquency, self-harm (cutting, burning, poisoning, or hanging oneself, jumping from heights, running into traffic) and suicidal ideation [43]. The danger was graphically illustrated by four cyber bullying related suicides of teenagers within six months alone at one secondary school [44].

Cyber suicide and its resulting introduction of legislation will see the rise of conviction for cyber bullying. Sexting and potential charges for the possession of child exploitation (child pornography) are recent trends, which will need to be addressed to prevent future ruin of potential employment prospects for those involved.

Significant funding by national and state governments, child protection authorities and educational organizations is dedicated to design and implement prevention and intervention programs. However, cyber bullying incidents have risen over the past years [13]; [20] cyber suicide and more recently sexting are emerging which questions the impact of those cyber safety initiatives. Given the large amounts of public monies invested into these prevention and intervention programs, systematic and rigorous evaluation of their effectiveness is overdue.

\section{Conclusion}

Banning electronic devices or installing internet filters will not solve the problem or prevent cyber bullying. Fundamentally, young people need to be taught how to protect themselves online, what their rights and responsibilities are in the use of digital media, and the possible consequences resulting from their recorded online transgressions (i.e. death threats, homophobia, sexist and racial slurs). However, currently prevention and intervention programs have not delivered the anticipated reduction in cyber bullying behavior. Therefore, careful and methodical evaluation of these attempts to improve online safety is essential to gain the desired outcomes in the reduction of cyber bullying.

\section{References}

[1] Organisation for Economic Co-operation and Development (OECD) (2001). The future of the internet economy. A statistic profiler. Retrieved December 10, 2011 from http://www.oecd.org/dataoecd/24/5/ 48255770.pdf

[2] Australian Communications and Media Authority (ACMA). (2008). Communications Report 
2007-08. http://www.acma.gov.au/WEB/STANDARD/ pc=PC_311541\#. (Access date: February 1, 2011)

[3] Australian Bureau of Statistics (2011).4102.0 Australian Social Trends, June 2011. Retrieved August 10, 2012 from http://www.abs.gov.au/AUSSTATS/abs@.nsf/ Lookup/4102.0Main+Features60Jun+2011

[4] Australian Bureau of Statistics (2009). Children's participation in cultural and Leisure Activities, Australia. Catalogue No 8146.0.

[5] Cowie, H. and Colliety, P. (2010). Cyberbullying: Sanctions or sensitivity? Pastoral Care in Education: An International Journal of Personal, Social and emotional Development. (28), 4, 261-268.

[6] Lenhart, A., Purcell, K., Smith, A. and Zickuhr, K. (2010). Social media \& mobile internet use among tee ns and young adults. Pew Internet \& American Life. Retrieved December 6, 2011 from http://pewinternet.org/ Reports/2010/Social-Media-and-Young-Adults.aspx

[7] Livingstone, S., Haddon, L., Görzig A., Ólafsson. K.(2011). Risk and safety on the Internet. The perspective of European children. Retrieved June 12, 2012 from http://www2.lse.ac.uk/media@1se/research/EUKidsOnline/ E U\%20Kids\%20II\%20(200911)/EUKidsOnlineII Reports/D4FullFindings.pdf

[8] Livingstone, S., Görzig, A., \& Ólafsson, K (2011).Disadvantaged children and online risk. EU kids Online network report. London, UK. Retrieved June 6, 2012 from http://eprints.lse.ac.uk/39385

[9] Mishna, F., Khoury-Kssabri, M., Gadalla T. and Daciuk, J.(2011). Risk factors for involvement in cyber bullying: Victims, bullies and bully-victims. Children and Youth Services. Elsevier. (34),1, 63-70.

[10] Herring, S.C. (2002) Cyber violence: Recognizing and resisting abuse in online environments. Asian women, 14, 187-212.

[11] Willard, N.E. (2003). Off-campus, harmful online student speech. Journal of School Violence. 1(2), 65-93.

[12] Kowalski, R.M., \& Limber, S.P. (2007). Electronic bullying among middle school students. Journal of Adolescent Health, 41, 22-30.

[13] Finklehor, D., Mitchell, K.J., \& Wolak, J. (2000). Online victimization: A report on the nations' youth. Alexandria, VA: National Center for Missing and Exploited Children.

[14] Hanewald, R. (2008). Confronting the Pedagogical Challenge of Cyber Safety. Australian Journal of Teacher Education, June 2008, 33 (3).

[15] Li, Q. (2004). Cyber-bullying in school: nature and extent of adolescents' experience. Retrieved October 22, 2007 from http://www.ucalgary.ca/ qinli/ publication/cyberbully_aera05\%20.html
[16] Shariff, S. (2005). Cyber-Dilemmas: Gendered Hierarchies, Free Expression and Cyber-Safety in Schools. Presented at "Safety and Security in a Networked World: Balancing Cyber-Rights and Responsibilities" Oxford Internet Institute Conference, Oxford, UK, September 810, 2005, Retrieved January 10, 2008 from http://www.oii.ox.uk/research/cybersafety/extension/pdfs/p apers/shaeen_shariff.pdf

[17] Hanewald, R. (2009). Cyberbullying research: The current state. Australian Educational Computing, July 2009, 24, (3), 10-15.

[18] i-Safe (2005). i-Safe Survey 2003-05. http://www.isafe.org/channels/sub.php?ch=op\&sub_id=me dia_digital_divide (Access date: June 10, 2011).

[19] National Children's Home (NCH) (2005). Putting U in the picture. Mobile bullying survey 2005

http://www.nch.org.uk/uploads/documents/Mobile_bullyin g_\%20report.pdf (Access date: May 14, 2008)

[20] Wolak, J., Mitchell, K., and Finkelhor, D. (2006). Online victimization of youth: Five years later. National Center for Missing \& Exploited Children Bulletin - \#0706-025. Alexandria, VA. (CV138)

[21] Campbell, M. (2005). Cyberbullying: An old problem in a new disguise? Australian Journal of Guidance and Counselling, 15 (1) 68-76

[22] Li, Q. (2004). Cyber-bullying in school: Nature and extent of adolescents' experience.

http://www.ucalgary.ca/ qinli/publication/cyberbully_aera 05\%20.html (Access date: May 14, 2011).

[23] Popovic-Citic, Djuric and Cvetkovic (2011) The prevalence of cyberbullying among adolescents: A case study of middle schools in Serbia. School Psychology International. 32 (4) 412-424.

[24] Smith, P., Mahdavi, J.; Carvalho, M.; \& Tippet, N. (2006). An investigation into cyber bullying, its forms, awareness and impact, and the relationship between age and gender in cyber bullying. A Report to the antiBullying Alliance. London. UK. http://www.antibullyingalliance.org/ (Access date, May 14, 2009).

[25] Slonje, R. \& Smith, P.K. (2007). Cyberbullying: Another type of bullying? Scandinavian Journal of Psychology, 49, 147-154.

[26] Mark, L. and Ratliffe, K.T. (2011). Cyber Worlds: New Playgrounds for Bullying. Computers in the Schools, Vol. 28 p 92 - 116. Routledge.

[27] Dooley, J. J.; Gradinger, P.; Strohmeier, D.; Cross, D. and Spiel, C. (2010). Cyber-

Victimization: The Association Between HelSeeking Behaviors and Self- Reported Emotional Symptoms in Australia and Austria. Australian Journal of guidance and counseling, Vol 20, No 2, pp. 194-209.

[28] Price, M. and Dalgleish, J. (2010). Cyberbullying. Experiences, impacts and coping strategies as described by 
Australian young people. Youth Studies Australia. Vol 29, No 2.

[29] Cross, D., Shaw, T., Hearn, L., Epstein, M., Monks, H., Lester, L.,. (2009). Australian Covert Bullying Prevalence Study (ACBPS). Perth, Australia: Child Health Promotion Research Centre, Edith Cowan University

[30] Chu, J. (8 August 2005). You Wanna Take this Online? Cyberspace is the 21 st century bully's playground where girls play rougher than boys. Time. Toronto.: ONT. $42-43$.

[31] Ybarra, M. L. \& Mitchell, J.K. (2004). Online aggressor/targets, aggressors and targets: A comparison of associated youth characteristics. Journal of Child Psychology and Psychiatry, 45, p 1308 -1316.

[32] Beran,T., \& Li, Q. (2007). The relationship between cyber bullying and school bullying. Journal of Student Wellbeing, 1, (2), 15-33.

[33] Mitchell, K.J.; Ybarra, M. \& Finkelhor, D. (2007). The relative importance of online victimization in understanding depression, delinquency, and substance abuse. Child Maltreatment, 12, 413-324

[34] Perren, S., Dooley, J. Shaw, T and Cross, D. (2010). Bullying in school and cyberspace: Associations with depressive symptoms in Swiss and Australian adolescents. Child and Adolescent Psychiatry and Mental Health, 4:28

[35] Netalert (2011). Protecting Australian Families Online.Australian Government.http://www.netalert.gov.au/ (Access date: February 11, 2011).

[36] Cybersmart (2011). Australian Communications and Media Authority. Australian Government.

http://www.cybersmart.gov.au/ (Access date: February 12, 2011).

[37] Higginbottom, N. \& Packham, B. (2007, August 27) Student cracks government 85 M porn filter. Herald Sun. http://www.news.com.au/story/02359922304224-

421,00html. (Access date: September 13, 2007).

[38] Li, Q. (2006). Cyber-bullying in schools: A research of gender differences. School Psychology International, 27 (2), 157-170.

[39] Smith, P., Mahdavi, J.; Carvalho, M.; Fisher, S., Russell, S. \& Tippet, N. (2008) Cyber bullying: Its nature and impact in secondary school pupils. Journal of Child Psychology and Psychiatry, 49, (4) 376-385.

[40] Hinduja, S. and Patchin, J.W. (2010). Sexting Fact Sheet. Cyber Bullying Research Centre. Retrieved August 4, 2011 from http://cyberbullying.us/blog/ sexting-research- and-gender-differences.html

[41] Hearn, L. (2010) Teens in trouble for sexting like the stars. The Sydney Morning Herald Sun, Digital Life, 28 October 2010. Retrieved August 4, 2011 from http://www.smh.com.au/digital-life/mobiles/teens-introuble-for-sexting-like-the-stars-20101028-174sn.html
[42] Atkin, M. (2011). Anti-sexting campaign branded dull, unrealistic. Australian Broadcasting Corporation, 15 April 2011. Retrieved on 4 August 2011 from http://www.abc.net.au/lateline/content/2011/s3193279.htm

[43] Hay, C., Meldrum, R. and Mann, K., (2010) Traditional bullying, Cyber Bulling and Deviance: A General Strain Theory Approach. Journal of Contemporary Criminal Justice, Vol. 26, page 130-147.

[44] Lannen, D. ( 2009) School's heartache after fourth student takes own life. 21 July 2009, Geelong Advertiser. http://www.geelongadvertiser.com.au/article/2009/ 07/21/86371_news.html. (Access date: March 26, 2011). 